\title{
The effectiveness of social skill training on depressive symptoms, self- esteem and interpersonal difficulties among Schizophrenic patients
}

\author{
Maaly. I. El Malky *, Merfat. M. Attia, Faten. H.Alam \\ Department of psychiatric Mental Health Nursing, Faculty of Nursing, Menoufia University, Shebin El-Kom, Egypt \\ *Corresponding author E-mail: Mervatatia@yahoo.com
}

\begin{abstract}
Patients with social skills deficits such as problems with communication with other people, social withdrawal, problems with activities of daily living should be offered to social skills training. Patients with schizophrenia usually have social skills deficits. Social skills training is a set of systematic techniques and strategies useful for teaching interpersonal skills that are based on social learning theory. It is a widely used treatment of a range of psychiatric disorders as schizophrenia. The aim of this study was to examine the effectiveness of social skill training program on self-esteem, depression and interpersonal difficulties among schizophrenic patients. Design: Quasiexperimental design (one group pretest posttest design) was used to achieve the aim of the study. Setting: The study was conducted at The Psychiatric Hospital in Tanta and the Psychiatric Hospital in Mit-Khalf at Menoufyia, Egypt. Sample: A convince sample (50) was selected in the chosen setting inpatient department. Tools: four tools were used for data collection. Tool one: a structured: sociodemographic questionnaire to obtain demographic data about the studied sample. Tool two: The depression, anxiety and stress scale (DASS).In this paper the researcher used the depression scale only which consists of 14 items in the form of rating scale. The depression scale assesses dysphoria, hopelessness, and devaluation of life, self- deprecation, and lack of interest and anhedonia. Tool three: SelfEsteem Inventory Scale: It evaluates attitudes of individuals toward themselves and consists of 25 items. Tool four: Relationship Scales Questionnaire. It consists of 13 items five points Likert- scale. The results: There is a highly significant reduction of the mean score of depressive symptoms and interpersonal difficulties at 0.001 while highly significant increase of the mean score of self-esteem at 0.001 post program than pre program. Conclusion: The social skills training program had a positive effect on interpersonal difficulties, depressive symptoms and self-esteem of the schizophrenic patients after receiving social skill training program. Recommendations: Generalized of social skill training program for all psychotic patients in hospital to improve their social competence and self-esteem.
\end{abstract}

Keywords: Schizophrenia; Social Skill; Social Skill Training.

\section{Introduction}

Communication skills are important to overall well- being, for creating positive interpersonal atmosphere and for solving interpersonal problems. Many patients suffering with various psychiatric disorders suffer from either a state-dependent decrease of social skills or lifelong deficits of such skills. Patients with social skills deficits such as problems with communication with other people, social withdrawal, problems with activities of daily living should be offered to social skills training. Social skills training is a set of systematic techniques and strategies useful for teaching interpersonal skills that are based on social learning theory. It is a widely used treatment of a range of psychiatric disorders as schizophrenia (Videbeck, 2011).

Schizophrenia is a complex and debilitating brain disorder that typically emerges in late adolescence and early adulthood and is characterized by hallucinations and delusions (commonly known as positive symptoms), social withdrawal, a logia, and flat affect (negative symptoms), and cognitive disabilities(Gogtay et al.2011)Moreover, schizophrenia is characterized by prominent impairments in social and role functioning, also poor social skills, which relate to the cognitive impairment associated with the illness, are a fundamental feature of schizophrenia that persists from the onset of the illness into older age (Mueser et al.,2010) Poor social skills and abnormal behaviors are key features of schizophrenia and comprise important aspects of social functioning. Poor social skills also seem to be related to the presence of negative symptoms (Brüne et al.2010) Generally, patients with schizophrenia usually have social skills deficits, which include an inability to communicate effectively with people, to confirm and express their negative or positive feelings, to make a request or to refuse unreasonable demands from others, and to understand interpersonal boundaries. Individuals with schizophrenia are known to have a lower self-esteem and depressive symptoms compared to the general population. Self-esteem refers to the overall opinion, we have of ourselves, how we judge or evaluate ourselves, and the value we attach to ourselves as people (Fennell, 2009). Low selfesteem in schizophrenia could be due to social stigma, paternalistic care, and long periods of institutionalization, interpersonal difficulties and negative family interactions (Borras ET al.2009).

Schizophrenic patients who display unstable levels of selfesteem are more likely to exhibit poorer responses to treatment and have a poorer quality of life than those with more stable selfesteem (Pedersen,2012)and (Vieru,2012). Although, antipsychotic medications the standard treatment for schizophrenia, are generally quite effective in reducing the positive symptoms of schizophrenia, they have only a modest effect on the negative symptoms 
of schizophrenia. Social skill training helps to improve negative symptoms when combined with medication treatment (Bharathi et al.2011). It became clear that improvements in social functioning will not occur through gains in psychotic symptom management alone. Instead, psychosocial interventions as social skills training that directly address the key determinant of poor social functioning are required to ameliorate this impairment (Kern et al.2009). In this regard, social skill training has been widely used as an effective mean of counteracting the social deficits of schizophrenic patients through training (Pfammatter et al.206). Clients with schizophrenia can improve their social competence with social skills training, which translate into more effective functioning in the community (Videbeck, 2011). In this sense, schizophrenic patients with deficits in the social skills needed for everyday activities which offered opportunities to participate in skills training in order to improve social interactions and other skills needed for independent living. The key elements in social skill training include behaviorally based instruction, role modeling, rehearsal, corrective feedback, and positive reinforcement. There is a substantial body of evidence that indicates that persons diagnosed with schizophrenia are capable of learning interpersonal and everyday living skills when provided with structured behavioral training that focuses on clearly defined activities, situations, and problems (Shean, 2013).

\section{Significance of the study}

Schizophrenia is a group of disorders in which biological, psychological, and socio-cultural factors interact synergistically during all phases of the disorder to result in impairments in interpersonal, practical life skills, and vocational functioning (Shean,2013).Unfortunately, schizophrenia is the most common chronic psychosis in Egypt, and represents the major bulk of patients in our mental hospitals. It affects $1 \%$ of the population worldwide and is equally found in different countries, with different cultures and both genders. Because of its chronicity and severity, schizophrenia is a major cause of disability, social dysfunction, unemployment, poverty and homelessness. World health report has listed it as the eighth leading causes of disability (Okasha, 2005).

Numerous studies have found that about one in every 100 people around the world has the schizophrenic disorder (Duckworth, 2010). There is no evidence that the incidence and prevalence figures in Egypt for schizophrenia would differ from those found in other parts of the world. If the assumption is true, it could be estimated that the number of persons in Egypt with schizophrenia would be within 0.5-1.5 million in Egypt with schizophrenia and some 10000-25000 new schizophrenic group psychosis should appear yearly. With the present population growth rate these figures will double in about 40 years and be tenfold in 104 years (Zahran et al.2006).

Schizophrenic patients have the right to life, like all people, they have the ability and energy to operate within their environment. Individuals living with schizophrenia typically have important goals for themselves in the areas of relationships, work and living. Schizophrenic patients have particular difficulty with the social skills of interpersonal relations, assertiveness, expression of thoughts and feeling to fulfill their life role in the community. Social skill training serves to extend and create more flexibility in the individual's communication style so that he or she has a greater choice of responses in various situations. Although a change does not come easy, social skill training can be an effective way of changing behavior. Psychiatric nurses are the front-line providers of care; they are the group called on most often to carry out selective reinforcement, modeling, extinction, skills training, shaping, and role playing. Because of their direct patient contact, nurses are better able to observe patients, assess problem areas, and recommend targets for cognitive behavior interaction. Nurses also may function as planners and coordinators of complex treatment program (Stuart, 2009). Teaching assertive communication skills are an important nursing intervention, nurses assist clients to learn and practice assertive communication skills, as well as using assertive communication to communicate with other nurses and members of the health care team (Videbeck, 2011).Nurses can assist patients to become more assertive, thereby encouraging them to become what they want to be, promoting their self-esteem and fostering a respect for their own rights and the rights of others (Videbeck, 2011).So, social skill training is designed to enable schizophrenic patients to compensate for or eliminate the environmental and interpersonal barriers as well as the functional deficits created by this illness

\section{Operational definition}

Social skill training is operationally defined as the social training that was given to schizophrenic patients to enable them to compensate or eliminate the environmental and interpersonal barriers as well as the functional deficits created by their illness.

Depressive symptoms are operationally defined as obtained individual depressive symptoms score measured by the depression, anxiety and stress scale (DASS).

Self-esteem is operationally defined as obtained individual self-esteem score measured by Self- Esteem Inventory Scale.

Interpersonal difficulties are operationally defined as obtained individual, interpersonal difficulty score measured by Relationship Scales Questionnaire.

\section{Subjects and methods}

\subsection{The Aim of the study}

The aim of the study is to examine the effectiveness of social skill training program on depression, self-esteem and interpersonal difficulties among schizophrenic patients.

\subsection{Research hypothesis}

Application of social skill training program on depressive symptoms, self-esteem and interpersonal difficulties among schizophrenic patients will improve depressive symptoms, self-esteem and interpersonal difficulties among schizophrenic patients.

\subsection{Research design}

Quasi-experimental design (one group pre test post test design) was used to achieve the aim of the study.

\subsection{Research Setting}

The study was conducted at The Psychiatric Hospital in Tanta and the Psychiatric Hospital in Mit-Khalf at Menoufyia, Egypt.

\subsection{Subjects}

A convince sample (50) was selected in the chosen setting inpatient department.

\subsubsection{Inclusion criteria}

- Hospitalized Patients who had psychotic disorders, oriented and accept to participate in the study.

- Patients aged from 18-59 under treatment therapy both sexes.

- Patients who are able to communicate verbally.

\subsubsection{Exclusion criteria}

- Patients aged 60 or more this older group might have physical health problems, making the intervention more difficult to implement

- $\quad$ Those who were being treated for substance misuse. 


\subsection{Instruments of the study}

Three tools were used in this study:

Tool (1): Semi-structured interviewing questionnaire:

Which include socio-demographic characteristics, including: age, sex, and premorbid personality.

Tool (2) the depression, anxiety and stress scale (DASS) by (Lovibond \&Lovibond, 1995)

- The depression, anxiety and stress scale (DASS) by (Lovibond \&Lovibond, 1995) were translated into Arabic and validated by (Kotb, 2007). The DASS is a 42- questionnaire which includes three self-report sub-scales designed to measure the negative emotional states of depression, anxiety and stress. In this paper the researcher used the depression scale only which consists of 14 items. The depression scale assesses dysphoria, hopelessness, and devaluation of life, self- deprecation, and lack of interest and anhedonia. Scores for depression are calculated by summing the scores for the relevant items.The total score ranges from 14-56. The higher score indicates negative emotional status.

Tool (3) Self- Esteem Inventory Scale:

- This tool was developed by Coopersmith, (1967). It evaluates attitudes of individuals toward themselves and consists of 25 items.

- Item number $1,2,3,6,7.10,12,13,15,16,17,18,21,22,23,25$ are given One point for each item answered "unlike me"and zero for item"like me

- Items number 4, 5,8,9,11,14,19,20,24 are given One point for each item answered "like me" and zero for item "unlike me".

- The total score for self-esteem was determined by dividing into prespecified levels: significantly below average (9-11), somewhat below average (12-14), average (15-18), somewhat above average (19-21), significantly above average (22-25)

Tool (4) Relationship Scales Questionnaire

- It was developed by Kurdek, (2002).It consists of 13 items a5 point Likert scale $(0=$ not at all like me to $4=$ very like me $)$ participants rate the extent to which each statement best describes their characteristic style in relationships. The higher score indicates difficulties in relationships.

\subsubsection{Reliability of the tools}

Reliability was applied by the researcher for testing the internal consistency of the tool, by administration of the same tools to the same subjects under similar conditions on one or more occasions. Answers from repeated testing were compared (Test-re-test reliability). The tool revealed strong reliability, tool one.85, tool two.91, tool three .94 .

\subsubsection{Validity of the tools}

They were tested for content validity by jury of five experts in the field of psychiatric Health Nursing and community nursing specialty to ascertain relevance and completeness. The tools proved to be valid.

\section{7. Procedure}

An administrative approval: was obtained from the dean of faculty of nursing and the director of The Psychiatric Hospital in Mit-Khalf and psychiatric hospital in Tanta. After explanation of the purpose of the study, the questionnaire used in the study was administered by the researcher.

Ethical consideration: the patients were briefed about the purpose of the study, encouraged and give fully informed verbal consent to participate. It was emphasized that all data collected was strictly confidential and the data would be used for scientific purposes only and the patient has full right to withdraw from the study at any time. A Pilot study was carried out 5 patients before starting data collection; this was done to estimate the time required for filling out the sheet and also to check the clarity of the tools. The sample of the pilot study was excluded from the study.

Data collection for the study was carried out in the period from October 2014 to December 2014. The researcher collected the data during the morning at two days/week from $10 \mathrm{AM}$ to $12 \mathrm{AM}$. The subjects were divided into 5 groups; each of them consisted of 10 patients. The period of implementation was 2 months. Implementation of the study passed into three phases (pre assessment phase, implementation phase and post assessment phase).

\subsubsection{Pre assessment phase}

A comfortable, private place was chosen for the interviewers. Orientation was done about the researcher's name, purpose, significance, content of the study. Subjects were interviewed individually at their rooms where pre- assessment was done using (1) Semistructured interviewing questionnaire, (2) The depression, anxiety and stress scale (DASS), (3) Self-Esteem Inventory Scale and (4) Relationship Scales Questionnaire

\subsubsection{Implementation phase}

This study hypothesized that Application of social skill training program on self-esteem, depression and interpersonal difficulties among psychiatric patients will improve self-esteem, depression and interpersonal difficulties among psychiatric patients. This training program has a general objective and divided into session each session has a set of specific objectives. This was achieved through several teaching methods such: brain storming, lecture, discussion, providing the example. Data show, video, role play and pictures were used as media. At the end of each session summary, feedback, further clarifications were done for vague items and a homework assignment for the next session.

The content of the intervention program sessions was as follows:

1) Introduction about the concept and nature of therapeutic nurse patient relationship, element, importance and barrier of effective communication in different situation.

2) How to use conversation skills and how to ask a variety of questions

3) Main principles in creating a therapeutic interpersonal relationship.

4) How to practice effective communication skills

5) How to use and practice social skills

6) The Facilitative interpersonal relationship.

7) Strategies that help patients to become more assertive.

8) Methods and strategies for developing self-esteem to the patient.

\section{General objective of the program.}

- $\quad$ Provide a trust relationship between the researcher and the client creates a space in which they can work together using the nursing process and their best possible efforts toward the goals.

- Encourage and help the client to spend short periods of time with another person (for example, have the client sit for 15 min of each hour during the day).

- Encourage and help the client to ventilate feelings in ways that are non-destructive and acceptable to the client such as writing, talking, drawing or physical activity the client direct verbal support, by using silence, by handling the client issues and give the client adequate time to ventilate.

- Interact on a one to one basis initially, then help the client progress to small groups and to larger groups as he/she can tolerate.

- Teach the client social skills and encourage the client to practice these skills with staff members and other clients such as:-

1) Eye contact with others during conversation

2) Smiling when greeting people

3) Shaking hands when meeting someone 
4) Using the right tone and volume of voice

5) Expressing opinions to others

6) Perceiving how others are feeling and showing empathy

7) Appropriate emotional responses (e.g. Crying when something sad happens; laughing when someone says something funny)

8) Give the client positive feedback regarding social interaction.

\subsubsection{Post assessment phase}

An evaluation was done using interpersonal relationships, selfesteem, and depression scales to assess the level of interpersonal relationships, self-esteem, and depression.

\subsection{Statistical analysis}

The results were statistically analyzed by SPSS version 16 (SPSS Chicago.Inc). Student's t-test, one a way ANOVA (F test), t test and paired $t$ tests were used for parametric data. Kruskal-Wallis, Mann-Whitney and Wilcox in signed rank tests were used for nonparametric data. Pearson's Correlation analysis was used to show strength and direction of association between two quantitative variables. $\mathrm{P}$ value $<0.05$ is considered significant.

\section{Results}

Table (1) Socio-demographic characteristics of the studied schizophrenic patients: this table reveals that the mean age is 31 , $88 \pm 7.10$, more than two third $(78 \%)$ were male, more than two third $(68 \%)$ were introverted.

Table (2) Effect of social skill training program on self-esteem, depressive symptoms and interpersonal difficulties among schizophrenic patients of the studied sample Post program: This table reveals that there is a highly significant reduction of the mean score of depressive symptoms and interpersonal difficulties at 0.001 while highly significant increase of the mean score of selfesteem at 0.001 post program than pre program.
Figure (1): Effect of social skill training program on difficulties of interpersonal relationship, self-esteem and depression among schizophrenic patients of the studied sample This figure shows that there is reduction of the mean score of depressive symptoms and interpersonal difficulties while increase of the mean score of self-esteem post program than before program.

Table 3: Relationship between depressive symptoms and Sociodemographic characteristics of the studied sample of schizophrenic patients' pre and post program: This table shows that there is no statistical significant difference between depressive symptoms mean score and all Socio-demographic characteristics of studied sample pre or post program.

Table 4: Relationship between self-esteem and Socio-demographic characteristics of the studied sample of schizophrenic patients' pre and post program: This table shows that there is no statistical significant difference between self-esteem mean score and all items of Socio-demographic characteristics of the studied sample pre or post program.

Table 5: Relationship between Interpersonal difficulties and Sociodemographic characteristics of the studied sample of schizophrenic patients: This table shows that there is no statistical significant difference between the mean score of interpersonal difficulties and all Socio-demographic characteristics of studied sample pre or post program.

Table (6): Correlation between difficulties of interpersonal relationship, self-esteem and depressive symptoms among

Schizophrenic patients of the studied sample pre and post program. This table shows that there is high positive correlation between depressive symptoms score and difficulties of interpersonal relationship pre and post program while negative significant correlation between self-esteem score and difficulties of interpersonal relationship pre and post program

N.B:- Positive significant correlation means when interpersonal difficulties increase, depressive symptoms increase. Negative correlation means when interpersonal difficulties increase selfesteem decrease.

Table 1: Socio-Demographic Characteristics of the Studied Sample

\begin{tabular}{lcc}
\hline Socio-demographic & Participants $(\mathrm{N}=50)$ & \\
Characteristics & $\mathrm{N}(50)$ & $\%$ \\
Age $(\mathrm{Y})$ & & $31.88 \pm 7.10$ \\
Mean $\pm \mathrm{SD}$ & & $19-54$ \\
Range & 39 & 78.0 \\
Sex & 11 & 22.0 \\
Male & 34 & 68.0 \\
Female & 16 & 32.0 \\
Pre-morbid personality & & \\
Introverted & & \\
Extroverted & & \\
&
\end{tabular}

Table 2: Effect of Social Skill Training Program on Self-Esteem, Depressive Symptoms and Interpersonal Difficulties Post Training Program.

\begin{tabular}{lllll}
\hline Items & Pre & Groups & Wilcoxon test & P- \\
\hline & Mean \pm SD & Mean \pm SD & & Value \\
Depression & $29.0 \pm 7.79$ & $21.40 \pm 7.37$ & 6.16 & $<0.001$ \\
Self-esteem & $13.24 \pm 3.66$ & $15.42 \pm 3.10$ & $* 11.67$ & $<0.001$ \\
Interpersonal & $26.90 \pm 7.90$ & $18.44 \pm 6.77$ & 6.16 & $<0.001$ \\
$\quad$ difficulties & & & & \\
*paired $t$ test & & & & \\
<0.001(HS) & & & \\
\hline
\end{tabular}




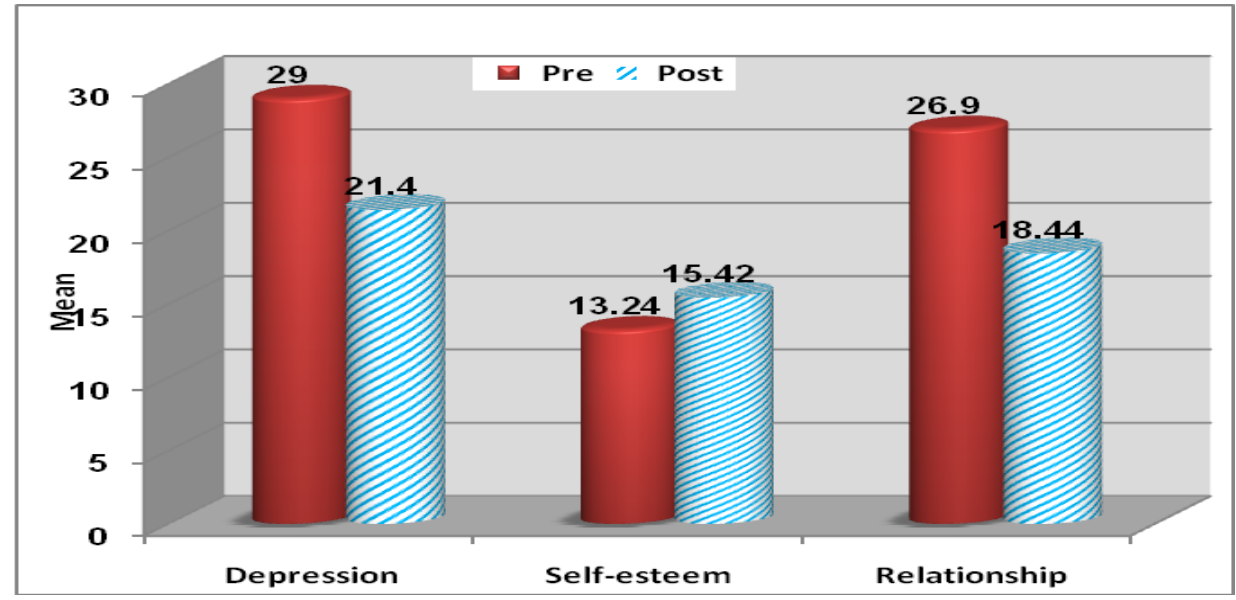

Fig. 1: Effect of Social Skill Training Program on Difficulties of Interpersonal Relationship, Self-Esteem and Depression among the Studied Sample of Schizophrenic Patients Post

Table 3: Relationship between Depressive Symptoms and Socio-Demographic Characteristics of Schizophrenic Patients' Pre and Post Program.

\begin{tabular}{|c|c|c|c|c|}
\hline Items of Socio- & & Depressive & & \\
\hline & Pre & & Post & \\
\hline & Mean \pm SD & Test & Mean \pm SD & Test \\
\hline & & $P$ value & & P value \\
\hline Age (Y) & & & & \\
\hline$\leq 30.5$ & $29.16 \pm 5.30$ & $\mathrm{MW}=0.32$ & $20.72 \pm 5.19$ & $\mathrm{MW}=0.11$ \\
\hline$>30.5$ & $28.84 \pm 9.78$ & $\mathrm{P}=0.748$ & $22.08 \pm 9.12$ & $\mathrm{P}=0.907$ \\
\hline Sex : & & & & \\
\hline Male & $29.02 \pm 7.70$ & $\mathrm{MW}=0.10$ & $21.51 \pm 7.39$ & $\mathrm{MW}=0.11$ \\
\hline Female & $28.90 \pm 8.47$ & $\mathrm{P}=0.916$ & $21.0 \pm 7.68$ & $\mathrm{P}=0.907$ \\
\hline Pre- morbid pers & & & & \\
\hline Introverted & $28.0 \pm 7.55$ & $t=1.33$ & $20.58 \pm 7.07$ & $\mathrm{MW}=1.27$ \\
\hline Extroverted & $31.12 \pm 8.10$ & $\mathrm{P}=0.189$ & $23.12 \pm 7.94$ & $P=0.204$ \\
\hline
\end{tabular}

Table 4: Relationship between Self-Esteem and Socio-Demographic Characteristics of Schizophrenic Patients' Pre and Post Program.

\begin{tabular}{|c|c|c|c|c|}
\hline \multirow[t]{2}{*}{ Items of Socio- } & \multicolumn{4}{|c|}{ Self-esteem } \\
\hline & Pre & & Post & \\
\hline \multicolumn{5}{|l|}{ Demographic } \\
\hline \multicolumn{2}{|l|}{ Characteristics } & & Mean \pm SD & Test \\
\hline Characteristics & & $\mathrm{P}$ value & & $P$ value \\
\hline \multicolumn{5}{|l|}{ Age (Y) } \\
\hline$\leq 30.5$ & $12.76 \pm 3.45$ & $\mathrm{t}=0.92$ & $15.20 \pm 2.73$ & $\mathrm{t}=0.49$ \\
\hline$>30.5$ & $13.72 \pm 3.87$ & $\mathrm{P}=0.360$ & $15.64 \pm 3.47$ & $\mathrm{P}=0.621$ \\
\hline \multicolumn{5}{|l|}{ Sex : } \\
\hline Male & $13.28 \pm 3.63$ & $\mathrm{MW}=0.28$ & $15.33 \pm 2.97$ & $\mathrm{MW}=0.29$ \\
\hline Female & $13.09 \pm 3.96$ & $\mathrm{P}=0.777$ & $15.72 \pm 3.66$ & $\mathrm{P}=0.768$ \\
\hline \multicolumn{5}{|c|}{ Pre-morbid personality } \\
\hline Introverted & $13.41 \pm 3.54$ & $\mathrm{t}=0.47$ & $15.58 \pm 2.95$ & $\mathrm{t}=0.55$ \\
\hline Extroverted & $12.87 \pm 4.01$ & $\mathrm{P}=0.634$ & $15.06 \pm 3.47$ & $\mathrm{P}=0.582$ \\
\hline \multicolumn{2}{|l|}{ Items of Socio- } & \multicolumn{3}{|c|}{ Interpersonal difficulties } \\
\hline Demographic & Pre & & Post & \\
\hline \multicolumn{5}{|l|}{ Characteristics } \\
\hline & Mean \pm SD & Test & Mean \pm SD & Test \\
\hline & & P value & & $P$ value \\
\hline \multicolumn{5}{|l|}{ Age (Y) } \\
\hline$\leq 30.5$ & $27.16 \pm 9.04$ & $\mathrm{t}=0.23$ & $17.80 \pm 9.46$ & $\mathrm{t}=0.66$ \\
\hline$>30.5$ & $26.64 \pm 6.76$ & $\mathrm{P}=0.819$ & $19.08 \pm 6.09$ & $\mathrm{P}=0.510$ \\
\hline \multicolumn{5}{|l|}{ Sex : } \\
\hline Male & $27.35 \pm 7.68$ & $\mathrm{MW}=0.76$ & $18.97 \pm 6.47$ & $\mathrm{MW}=1.16$ \\
\hline Female & $25.27 \pm 8.84$ & $\mathrm{P}=0.446$ & $16.54 \pm 7.77$ & $\mathrm{P}=0.245$ \\
\hline \multicolumn{5}{|c|}{ Pre-morbid personality } \\
\hline Introverted & $25.67 \pm 7.67$ & $\mathrm{t}=1.62$ & $17.38 \pm 6.82$ & $\mathrm{MW}=1.80$ \\
\hline Extroverted & $29.50 \pm 7.99$ & $\mathrm{P}=0.111$ & $20.68 \pm 6.28$ & $\mathrm{P}=0.071$ \\
\hline
\end{tabular}


Table 6: Correlation between Patient's Difficulties of Interpersonal Relationship, Self-Esteem and Depressive Symptoms Pre and Post Program

\begin{tabular}{lllll}
\hline \multirow{2}{*}{ Items } & \multicolumn{2}{c}{ Difficulties of interpersonal relationship } \\
\cline { 2 - 4 } & & Pre & Post \\
Depression & $\mathrm{R}$ & P value & r & 0.367 \\
Self-esteem & 0.442 & 0.001 & -0.218 & 0.009 \\
& -0.286 & 0.044 & 0.129 \\
\hline
\end{tabular}

\section{Discussion}

Social skill training is best appropriate for the patients who are experiencing psychosocial problems and lowering self-esteem such as schizophrenia that is at least partly caused or exacerbated by interpersonal difficulties, such as a trouble initiating new relationships, lack of close friends, strained relationships with coworkers, marital distress, frequent quarrels, difficulties in reaction to critique, to say no, and to express own wishes or feelings (Granhol et al. 2007) and (Kurtz\&Mueser, 2009). Assertiveness training is a life skill that causes an increase in self-esteem, rationale stating of thoughts and feelings, anxiety reduction, improvement in social and relational skills, respecting other's right and increasing the rate of satisfaction from life and happiness (Hashemi, 2007).

The present study reveals that the mean age is $31,88 \pm 7.10$. This finding is consistent with (Mousa et al. 2011) who found that near to half of the sample, their age ranging from 30 years to less than 40 years. This result also agrees with (Khalil, 2012) who showed that near to half of the sample, their age ranging from 29 to 40 years. As regards to the comparison between the mean changes of interpersonal skills scores pre and post program implementation. It was found that, a highly statistically significant reduction of interpersonal difficulties mean scores of studied sample post program implementation. This could be due to the positive effect of social skill training for improving social skills of the studied sample. This result demonstrates that in spite of their serious deficits, persons with schizophrenia are capable of learning a wide range of social skills. Other possible reasons for improvement in social skills, participants were instructed to behave assertively in role-playing situations. During the role playing and practice in the training, participants were encouraged to praise each other using positive verbal affirmations, which encouraged assertive performance. This helped each participant acquire a positive self-perception and explore effective techniques for selfexpression. This may partially explain the highly significant improvement in interpersonal difficulties measured among schizophrenic patients after participation in social skill training program A probable reason for decreasing interpersonal difficulties may be due to the fact that participation in the program has helped the less assertive schizophrenic patients to reach and practice assertive behaviors in communicative conditions with others in a real and natural way and use them in a right manner. In addition, completing the social skill training program was helpful to understand the concept of assertive behavior and differentiate it from other behaviors.

This result is congruent with (Lee et al .2013) who found that among patients with chronic schizophrenia, assertiveness level significantly improved immediately after assertiveness training intervention in the intervention group. On the same line, this result is also in agreement with a study carried out by (Seo et al. 2007) about social skill training as a nursing intervention to improve the social skills and self-esteem of patients with chronic schizophrenia. His training program has been of two parts; conversational skills and assertiveness skills. The conversational skill, interpersonal relationship, assertiveness and self-esteem of experimental group have shown significant improvement. This result comes in accordance with a study by (Han ET al.2005) his study was designed to examine the effects of an assertiveness training program on interpersonal relations in patients with a mental disorder. Who declared in their results that there were greater significant increases in scores of interpersonal relations and content of communica- tion in the experimental group than the control group? In the same line, (Pfammatter et al. 2006) investigated the effects of social skill training (SST) on measures skills acquisition, assertiveness, social functioning. Results from this analysis yielded large effects of SST on skills acquisition, with smaller, but significant, effects on assertiveness, social functioning This finding is in agreement with (Lin et al. 2008) who stated that patients would benefit more from the assertiveness training program for the change in how they view themselves, improve their assertiveness, properly express their individual moods and thoughts and further establish self-confidence. In the same line, (Hou et al. 2004) added that, assertiveness training can improve patient's social skills and emotional health which is a process of learning to stand up for one's rights and cope assertively, not passively or aggressively. While, on the other side this finding disagreement with (Cheung \& NG, 2006), who reported that SST has no benefit for in patients with severe chronic schizophrenia. Also, this result is in disagreement with a study conducted by (Lauterbach et al.1979) who pointed out that almost all experimental studies of group treatments with psychiatric patients have shown no significant results for assertive or social skills training. Comparing between the mean changes of self-esteem scores of the studied sample post program implementation, the present study shows that there was a highly statistically significant improvement of the mean score of self-esteem post program implementation. This means that there is a positive effect of social skill training program on level of self-esteem of schizophrenic patients who participated in the program. This result is consistent with (Pan\& Dai, 2008) and (Seo et al. 2007) who found that enhanced self-esteem of the experimental group after participating in the social skill training program. In this respect, this result is in agreement with (Hashemi, 2007) who stated that assertiveness training is a life skill that causes an increase in selfesteem, rationale stating of thoughts and feelings, anxiety reduction, improvement in social and relational skills, respecting other's rights and increasing the rate of satisfaction in life and happiness.

In the same line (Kashani\&Bayat, 2010) who stated that assertiveness training is an effective and useful way for less assertive and shy people to state their positive or negative emotions easily and express themselves and get the required self-esteem. This result also is consistent with previous studies by (Shimizu et al. 2004) and (Lin et al. 2004), who found that self-esteem of the experimental group was significantly improved after the assertiveness training program. On the other hand, this finding is not consistent with the previous study by (Killaspy et al. 2006), who found that the outcomes of his study have not shown that assertiveness training increases the patient's self-esteem in acute psychiatric settings Comparing between the mean changes of depressive symptom scores of the studied sample post program implementation, the present study shows that there was a highly statistically significant reduction of the mean score of depressive symptoms post program implementation. This means that the program shows a positive effect on the level of depression among schizophrenic patients. This result is consistent with (Michel, 2008) and (Michel, 2008) who founded that People who are more assertive tend to be less depressed and have better health outcomes. Less assertive people have a greater low self-esteem, and likelihood of substance abuse. Moreover, may experience depression, resentment, frustration, temper, anxiety, relationship difficulties, and stress-related problems (Alwan \& Reeve, 2005). In the same line (Segrin, 2008) and (Kopelowicz et al. 2006), Stated that SST is improving the quality of patient's interpersonal communication and relationships and reducing their psychiatric symptoms. 
The present study result reveals that there were statistically significant negative correlation between self-esteem and difficulty of interpersonal relationship of the studied samples pre and post program implementation. This means that when interpersonal difficulties decrease self-esteem increase. This result is consistent with (Tavakoli et al. 2014), who reported that assertiveness and self-esteem have a direct strong relationship with each other in the same line, (Ratson, 2011) stated that assertiveness promotes low self-esteem and social anxiety. While, on the other hand, the low level of self-esteem will result in many psychological, physical, and social problems. (Shimizu et al. 2004) Pointed out that there were a two way relationship between assertiveness and selfesteem. It seems that assertiveness causes an increase in selfconfidence, interpersonal relations, and internal control. This result corresponded to the previous results by (Ibrahim, 2010) and (Kirst, 2011), who found a high level of assertiveness correlated positively and significantly with a high level of self-esteem, as when the person being assertive can help to boost their level of self-esteem. This result is consistent with (Marcon, 2010), who stated that positive self-esteem is a vital prerequisite to become assertive and to getting other people to respect one's rights.

The present study reveals positive correlation between interpersonal difficulties and depressive symptoms this is mean when interpersonal difficulties increase depressive symptoms increase. This is consistent with ( $\mathrm{Ku}$ et al. 2007) Who founded that lack of assertiveness can lead to many problems, including: Saying 'yes' when you should be saying "no", anxiety about previous actions, social isolation due to anxiety about interactions or over hostile behavior, low self-esteem and depression. The present study results reveal that there were no a statistically significant relationship between level of self-esteem, depressive symptoms, interpersonal difficulties and their socio-demographic characteristics. This result corresponds with (Shamsunnisah\&Hasanah, 2008), who found that there was no association found between age, educational level, marital status, and personal income and the level of selfesteem and depressive symptoms of schizophrenia patients. While on the other side this result disagreement with (Hemmati ET al.2014), who stated that self-esteem is an important factor which had influence on age, educational level, income, and occupation of an individual. It can be said that, the social skill training nursing intervention program in the current study has made a positive contribution in developing social skill, reduce depressive symptoms and enhancing self-esteem of chronic schizophrenic patients. The results of the study contributed to the facts that assertive behavior can be learnt and self-esteem can be enhanced through assertiveness training (Abdel-Aleem, 2007). The results of this study were consistent with the study hypothesis that the social skill training program will improve social skills, reduce depressive symptoms and enhance self-esteem of schizophrenic patients.

\section{Conclusion}

The findings of the present study indicate that the social skills training program had a positive effect on interpersonal difficulties, depressive symptoms and self-esteem of the schizophrenic patients after receiving social skill training program. There was a highly statistically significant negative correlation between the total interpersonal difficulty and self-esteem level of the studied sample. While there was a highly statistically significant positive correlation between total interpersonal difficulty and depressive symptoms of the studied sample pre post program implementation. These conclusions lead to the acceptance of the study hypothesis that the social skill training program improved interpersonal skills, self-esteem and depressive symptoms of schizophrenic patients.

\section{Recommendations}

- Based on the previous findings of the present study, the following recommendations are suggested.
- Generalized of social skill training program for all psychotic patients in hospital to improve their social competence and selfesteem.

- Assertiveness training program can be used as an intervention in conjunction with pharmacological therapy without contraindications and it can maximize the effect in patients with chronic schizophrenia.

Further studies using a larger probability sample for generalization of the results.

\section{References}

[1] Videbeck, S. L. (2011): Psychiatric-mental health nursing. (5thed.). Walters Kluwer, Lippincott Williams \& Wilkins, China.PP.234266.

[2] Gogtay, N., Vyas, N. S., Testa, R., Wood, S., \&Pantelis, C. (2011): Age of onset of schizophrenia: Perspectives from Structural Neuroimaging Studies, Oxford Journals. Schizophrenia Bulletin, 37(3): 504-513. http://dx.doi.org/10.1093/schbul/sbr030.

[3] Mueser, K. T., Pratt, S. I., \& Cather, C. (2010): Neuro-cognition and social skill in older persons with schizophrenia and major mood disorders: An analysis of gender and diagnosis effects. Journal of Neurolinguistics. http://dx.doi.org/10.1016/j.jneuroling.2009.08.007.

[4] Brüne, M., Schaub, D., Juckel, G., \& Langdon, R. (2010): Socia skills and behavioral problems in schizophrenia: The role of mental state attribution, neurocognition and clinical symptomatology. Psy$\begin{array}{lll}\text { chiatry } & \text { Res, } & \text { 190(1): }\end{array}$ http://dx.doi.org/10.1016/j.psychres.2010.03.015.

[5] Fennell, M. (2009): Overcoming low self-esteem, a self -help guide using cognitive behavioral techniques. Create Britain, London. P: 7.

[6] Borras, L., Boucherie, M., Mohr, S., Lecomte, T., Perroud, N., \& Huguelet, P. (2009): Increasing self-esteem: efficacy of a group intervention for individuals with severe mental disorders European Psychiatry, 24: http://dx.doi.org/10.1016/j.eurpsy.2009.01.003

[7] Pedersen, T. (2012): Low self-esteem affects treatment outcomes in schizophrenia.http://psychcentral.com/news/2012/09/28/low-selfesteem-affects-treatment-outcomes-in-schizophrenia/45270.html. Retrieved on: 28/6/2013

[8] Vieru, T. (2012): Schizophrenia therapy efficiency reduced by low self-esteem. Available at:http://news.softpedia.com/newsImage/Schizophrenia-TherapyEfficiency-Reduced-by-Low-Self-Esteem-2.jpg/. Retrieved on: 10/4/2013.

[9] Bharathi, G. D., Huang, N., \& Lu, Z. (2011): Psychosocial Interventions for Patients with Schizophrenia. Shanghai Archives of Psychiatry, 23(6): 368-375.

[10] Kern, R. S., Glynn, S. M., Horan, W. P. \&Marder, S. R. (2009): Psychosocial treatments to promote functional recovery in schizophrenia. Schizophrenia Bulletin, 35(2): 347-361. http://dx.doi.org/10.1093/schbul/sbn177.

[11] Pfammatter, M., Tunghan, U. M., \& Brenner, H. D. (2006): Efficacy of psychological therapy in schizophrenia. Conclusion from meta-analysis. Schizophrenia Bulletin, 32(1): 564-580.

[12] Shean, G. D. (2013): Empirically based psychosocial therapies for schizophrenia: The disconnection between science and practice. Schizophrenia Research and Treatment.Article ID 792769, 8 pages. http://dx.doi.org/10.1155/2013/792769.

[13] Okasha, T. A. (2005): Mental Health in Egypt, Isr J Psychiatry RelatSciVol 42 No. 2, .116-125.

[14] Duckworth, K. (2010): Early onset schizophrenia. National alliance on mental illness. Available at:http://www. nami.org/ Template.cfm? Section = schizophrenia\&template $=/$ Content Management/Content Display. cfm\&ContentID $=103175$. Retrieved on: $1 / 5 / 2013$.

[15] Zahran, N. S., Khalil, A. H., Okasha, T. A., \& Adel Sadek, H. (2006): Systematic review of Egyptian studies on schizophrenia. (Published Master Desertion), Faculty of Medicine. Ain Shams University

[16] Stuart, G. W. (2009): Principles and practice of psychiatric nursing (9thed.). Mosby Elsevier. Canada. Pp: 580-575.

[17] Granhol m, E., McQuaid, J., McClure, F. S., Link, P. C, Pervoliotis, D., \& Gog-glieb, J.D. (2007): Randomized controlled trial of cognitive behavioral social skills training for older people with schizophrenia: 12-month follow-up. J Clin Psychiatry, 68: 730-737. http://dx.doi.org/10.4088/JCP.v68n0510. 
[18] Kurtz, M. M. \&Mueser, K. T. (2009): A meta-analysis of controlled research on social skills training for schizophrenia. Journal of Consulting and Clinical Psychology, 76: 491-504. http://dx.doi.org/10.1037/0022-006X.76.3.491.

[19] Hashemi, F. (2007): Effects of self-expression training on guidance school female students' happiness in Rey city [Thesis]. Tehran, Iran: Training Science Department, AllamehTabatabaei University.

[20] Mousa, A., Imam, S. \&Sharaf, A. (2011): The effect of an assertiveness training program on assertiveness skills and social interaction anxiety of individuals with schizophrenia. Journal of American Sci, 7(12): 454-466.

[21] Khalil, A. I. (2012): A Community based treatment: Impact of social skills training program on improving social skills among schizophrenic patients. World Applied Sciences Journal, 18(3): 370-378.

[22] Lee, T. Y., Chang, S. C., Chu, H., Yang, C, Y., Ou, K. L., Chung, M. H., \& Chou, K. R. (2013): The effects of assertiveness training in patients with schizophrenia: a randomized, single-blind, controlled study. J AdvNurs. http://dx.doi.org/10.1111/jan.12142.

[23] Seo, J. M., AhnAffiliations, S., Byun, K., \& Kim, C. (2007): Social skill training as a nursing intervention to improve the social skill and self-esteem of in patients with chronic schizophrenia. Arch $\begin{array}{lll}\text { PsychiatrNurs; } & 21(6) \text { : } & 317-\end{array}$ http://dx.doi.org/10.1016/j.apnu.2006.09.005.

[24] Han, K. S., Im, H. S., Yang, B. K., Chung, H. K., \&Suh, Y. J. (2005): Effects of assertive training on interpersonal relations, social behavior, and psychiatric symptoms in patients with a mental disorder. TaehanKanhoHakhoe Chi, 35(5): 896-903.

[25] Lin, Y., We, M., Yang, C., Chen, T., Hse, C., Chang, Y. Tzengw., Chou, Y. \& Chou, K. (2008): Evaluation of assertiveness training for psychiatric patients. Journal of clinical nursing, 17: 2875-2885. http://dx.doi.org/10.1111/j.1365-2702.2008.02343.X.

[26] Hou, S. Y., Sul, Y. C. \&Lan, C. M. (2004): Nurse's assertiveness training and cognitive therapy experiences with an outpatient suffering from low self-esteem. Journal of Nursing, 51: 97-103.

[27] Cheung, R., \& NG, R. (2006): Social skills training in Hong Kong Chinese patients with chronic schizophrenia, Hong Kong Journal of Psychiatry, 16: pp.14-20.

[28] Lauterbach, W., Pelzer. U., \&Awiszus, D. (1979): Is social skills training effective in European schizophrenics? Behar. Analysis Modif, (3): 21-31.

[29] Pan, L. Y., \& Dai, X. L. (2008): Study on comprehensive social activity skill exercise on improving the social adaptability of patients with schizophrenia in recovery stage. Nursing and Rehabilitation Journal, 7(5): 325-327.

[30] Kashani, B., \&Bayat, M. (2010): The effect of social skills training (assertiveness) on assertiveness and self-esteem increase of 9 to 11 year-old female students in Tehran, Iran World Applied Sciences Journal, 9(9): 1028-1032.

[31] Shimizu, T., Kubota, S., Mishima, N., \& Nagata, S. (2004): Relationship between self-esteem and assertiveness training among Japanese hospital nurses. J Occup Health, 46(4): 296-8. http://dx.doi.org/10.1539/joh.46.296.

[32] Lin, Y., Shiahb, I., Changc, Y., Laid, T., Wange, K., \&Chouf, K. (2004): Evaluation of an assertiveness training program on nursing and medical students' assertiveness, self-esteem, and interpersonal communication satisfaction. Journal of Nurse Education Today, 24:656- 65. http://dx.doi.org/10.1016/j.nedt.2004.09.004.

[33] Killaspy, H., Bebbinton, P., Blizard, R., Johnson, S., Nolan, F., Pilling, S \& King, M. (2006): The REACT study: Randomized evaluation of assertive community treatment in north London. British Medical Journal, 32: 815-820. http://dx.doi.org/10.1136/bmj.38773.518322.7C.

[34] M ichel F. (2008): Assert yourself. Module (6): How to Say "No" Assertively. Perth, Western Australia: Centre for Clinical Interventions.

[35] Michel, F. (2008): Assert yourself. Module (7): How to Deal Assertively with Criticism. Perth, Western Australia: Centre for Clinical Interventions.

[36] Alwan, C., \& Reeve, N. (2005): Assertiveness - A self-help guide. Norfolk and Waveney Mental Health Care NHS Trust.Avaliable at: www.heron.nhs.uk/.../assertiveness_self-help_large_prin. Retrieved on: $14 / 2 / 2014$.

[37] Segrin, C. (2008): Social skills training, in cognitive behaviora therapy: Applying empirically supported techniques in your practice. (2nded.), Wiley, New Jersey, p.502-509.

[38] Kopelowicz, A., Liberman, R. P. \&Zarate, R. (2006): Recent advances in social skills training for schizophrenia. Schizophrenia Bulletin, 32(S1): S12- S23. doi:10.1093/schbul/sb1023. http://dx.doi.org/10.1093/schbul/sbl023.
[39] Tavakoli, P., Setoodeh, G., Dashtbozorgi, B., Sani, K. \&Pakseresht, S. (2014): The influence of assertiveness training on self-esteem in female students of government high-schools of Shiraz, Iran: A randomized controlled trial. Nurs Pract Today, 1(1): 17-23.

[40] Ratson, M. (2011): The importance of assertiveness and self-esteem Availableat:http://www.spiral2grow.com/the-importance-of assertiveness-and-self-esteem/. Retrieved on: 7/9/2014.

[41] Ibrahim, S. (2010): Factors affecting assertiveness among student nurses. Journal of Nurse Education Today, 31(4): 356-60. http://dx.doi.org/10.1016/j.nedt.2010.07.006.

[42] Kirst, L. K. (2011): Investigating the relationship between assertiveness and personality characteristics. University of Central Florida Orlando, Florid.

[43] Marcon, N. (2010): Assertive rights-you're right to be treated well. Available at :( http://ezinearticles.com/?Assertive-Rights-YourRight-To-Be-Treated-Well\&id=4202679. Retrieved on: 15/4/2013.

[44] Ku, J., Han, K., Lee, H. R., Jang, H. J., Kim, K. U., \& Park, S. H. (2007): VR-based conversation training program for patients with schizophrenia: a preliminary clinical trial. Cyberpsychology\& Behavior, 10(4): 567-574. http://dx.doi.org/10.1089/cpb.2007.9989.

[45] Shamsunnisah, A. B., \&Hasanah, C. I. (2008): Self-esteem of out patients with schizophrenia: The association of self-esteem and socio-demographic and clinical characteristic. Priory Lodge Education Limited.

[46] Hemmati, M., Taghipour, M., \& Asgar, M. H. (2014): Investigation between self-esteem and assertiveness and employees performance in national Iranian bank, Journal of Applied Environmental Sciences and Biolog, 4(4):182-187.

[47] Abdel-Aleem, M. (2007): Factors affecting assertiveness among head nurses and staff nurses.(Unpublished Master Thesis). Faculty of Nursing. Suez Canal University, 46.

[48] Lovibond, S.H. \&Lovibond, P.f. Manual for the Depression Anxiety Stress Scales. (2nd Ed) Sydney: Psychology Foundation. 1995.

[49] Kotb F. Social support, psychological distress and suicidal tendency of depressed patient. Unpublished master thesis. Faculty of nursing, CairoUniversity.2007:170-172.

[50] Coopersmith, S. (1967). The antecedents of self-esteem. San Francisco: W. H. Freeman \& Co

[51] Kurdek, L. A. (2002).On being insecure about the assessment of attachment styles. Journal of Social and Personal Relationships, 19, 811-834. http://dx.doi.org/10.1177/0265407502196005. 